44 DO ORGANISATIONAL CHANGE IN OUT-OF-HOUR SERVICE INFLUENCE ON THE USE OF HELICOPTER EMERGENCY MEDICAL SERVICE? AN OBSERVATIONAL STUDY OF A NATURAL EXPERIMENT

\begin{abstract}
1,2DS Nystøyl* ${ }^{3}$ HJ Breidablik, ${ }^{1,4}$ J Røislien, ${ }^{2,5}$ S Hunskaar, ${ }^{6} \varnothing$ Østerås, $2,5 \mathrm{E}$ Zakariassen. ${ }^{1}$ Department of Research, Norwegian Air Ambulance Foundation, Drøbak, Norway; ${ }^{2}$ Research Group for General Practice, Department of Global Public Health and Primary Care, University of Bergen, Norway; ${ }^{3}$ Centre of Health Research, Førde Hospital Trust, Forde, Norway; ${ }^{4}$ Faculty of Health Sciences, University of Stavanger, Stavanger, Norway; ${ }^{5}$ National Centre for Emergency Primary Health Care, Uni Research Health, Bergen, Norway; ${ }^{6}$ Department of Anaesthesia and Intensive Care, Haukeland University Hospital, Bergen, Norway
\end{abstract}

\subsection{6/10.1136/bmjopen-2018-EMS.44}

Aim Over the last decades out-of-hour services in Norway have been centralised to cover lager geographical areas, resulting in longer response times for the on-call GP. Reports indicate an unintended increase in requests of helicopter emergency medical services (HEMS) as a result. We aimed to investigate alteration in the requests for HEMS and NACAscore of the patients transported.

Method In 2009 nine municipalities in the county of Sogn og Fjordane relocated all local out-of-hour services into one large casualty clinic (SYS-IKL). We included all primary HEMS requests in the county from 2004-2013 and compared missions within the area of SYS-IKL to missions in the rest of the county.

Results Preliminary data included 7310 requests. Within SYS-IKL requests were 4.4 per week in the period. Completed and cancelled requests were 3.0 and 1.3 per week before 2009 compared to 2.7 and 1.6 per week after 2009. Outside SYS-IKL requests were 8.9 per week before 2009 and 10.4 per week after 2009 . Completed and cancelled requests were 5.1 and 3.4 per week before 2009 compared to 5.5 and 4.6 per week after 2009. Mean NACA-score within SYS-IKL was 3.98 and $3.87(p=0.115)$ compared to 3.78 and $3.77(\mathrm{p}=0,786)$ outside SYS-IKL before and after 2009, respectively.

Conclusion Preliminary results did not confirm the hypothesised increase in use of HEMS or reduced NACA-score due to centralization of out-of-hour services. However, further statistical analyses are required.

Conflict of interest None

Funding Norwegian Air Ambulance Foundation.

\section{SATISFACTION OF PARAMEDICS AND PATIENTS IN THE USE OF METHOXYFLURANE (PENTHROX) FOR THE TREATMENT OF PAIN}

\footnotetext{
1,2J Karjanlahti* , 'M Tölli, 'V Lahola, 'S Länkimäki. 'Centre for Prehospital Emergency care, The Hospital District of South Ostrobothnia, Seinäjoki, Finland; ${ }^{2}$ Vocational Education Centre Sedu, Seinäjoki, Finland
}

\subsection{6/10.1136/bmjopen-2018-EMS.45}

Aim The objective of this study was to evaluate the satisfaction of paramedics and patients in the use of Penthrox in pain management.

Method The material was collected by using a questionnaire between Dec 2016-Dec 2017 in the Hospital District of South Ostrobothnia. Penthrox was given to 68 patients and the paramedics recorded both their own answers and those of the patients in the questionnaire.

Results The mean satisfaction of the paramedics in the use of Penthrox was 7.85 on a scale $1-10$ with a standard deviation (SD) of $2.36(n=61)$. A total of $40 \%$ of the respondents scored their satisfaction as $8-10$. The mean satisfaction of the patients was 8.04 with SD of $2.52(n=49)$ and $51 \%$ of the patients rated the satisfaction to be $8-10$. At baseline, the average pain of 65 patients was 8.09 with SD of 1.45 . The average pain at $10 \mathrm{~min}$ after dosing was 5.42 with SD of $2.45(n=64)$. Pain estimated at $10 \mathrm{~min}$ after dosing, a statistically significant difference was observed between pain at baseline $(p<0.001)$. Among the adverse effects, nausea occurred in one $(1.47 \%)$ and haemodynamic problems in two (2.94\%) patients $(\mathrm{n}=68)$.

Conclusion Based on this study, most of the paramedics and patients were satisfied with the use of Penthrox in the treatment of pain. Penthrox relieved pain in a statistically significant manner and among the adverse effects, the occurrence of nausea and haemodynamic problems was limited.

Conflict of interest None

Funding For the analysis and publication of the study results has been granted by Mundipharma Oy

\section{EMS-WIDE MULTIFACETED IMPLEMENTATION OF HEMS- PHYSICIAN PROVIDED RSI PROTOCOL}

${ }^{1} \mathrm{~S}$ Ångerman*, ${ }^{2} \mathrm{H}$ Kirves, ${ }^{1} \mathrm{~J}$ Nurmi. ${ }^{1}$ Helsinki University Hospital and Department of Emergency Medicine, Finland; ${ }^{2}$ Prehospital Emergency Care, Hyvinkää hospital area, Finland

\subsection{6/10.1136/bmjopen-2018-EMS.46}

Aim We developed a RSI protocol that standardises the prehospital process of anaesthetised patients and involved EMS crews as active team members. We recently reported the effect of the protocol on the intubation success rate. ${ }^{1}$ The aim of the current study was to describe the methods used during implementation of RSI protocol to the EMS systems and evaluate the protocol compliance and effect on on-scene time (OST).

Method The RSI protocol was implemented to the HEMS unit and EMS systems in a three months period in 2015. The implementation of the RSI protocol consisted of spreading material, lectures, simulations, skill stations, academic detailing and cognitive aids. Over 20 lectures and discussion panels were organised throughout the collaborative EMS systems. Training video was published in YouTube ( $>34.000$ views). The checklists are used by the EMS personnel preparing the patient for intubation, HEMS crew before the induction of anaesthesia and before starting the transportation. Data from RSI missions were gathered to a database before (201 patients in year 2014) and after the implementation of the protocol (468 patients in years 2015-2016).

Results The protocol compliance rate was 95\%-97\% (preoxygenation $\geq 3$ min 97\%, neuro-muscular blocking agent $97 \%$, mechanical ventilation 95\%). The median of OST was $31 \mathrm{~min}$ (IQR 23-38) before the protocol, and $28 \mathrm{~min}$ (IQR 22-37) after the implementation (P 0,0495). Reporting of complications was also improved.

Conclusion Using multifaceted implementation strategy and involving EMS crews in the protocol can significantly improve the clinical process of a HEMS unit.

\section{REFERENCE}

1. Ångerman $\mathrm{S}$, Kirves $\mathrm{H}$, Nurmi J. A before-and-after observational study of a protocol for C-MAC videolaryngoscope with Frova Introducer in prehospital rapid sequence intubation. Anaesthesia 2018.

Conflict of interest None

Funding None 